\title{
Septicemia em bezerro por Mannheimia haemolytica no estado de Pernambuco, Brasil
}

\author{
[Septicemia in a calf by Mannheimia haemolytica in the state of Pernambuco, Brazil]
}

\section{"Relato de Caso/Case Report"}

\section{Raylson Pereira de Oliveira ${ }^{\mathbf{1}}$, Rhaysa Allayde Silva Oliveira ${ }^{\mathbf{1}}$, Rômulo Freitas Francelino Dias ${ }^{\mathbf{2}}$, Alexandre Cruz Dantas ${ }^{1}$, Janaina Azevedo Guimarães ${ }^{1}$, Fabricio Bezerra de Sá ${ }^{3}$, Alice Maria Melville Paiva Della Libera ${ }^{4}$, Rinaldo Aparecido Mota ${ }^{1}$}

\author{
${ }^{1}$ Departamento de Medicina Veterinária, Universidade Federal Rural de Pernambuco, Recife-PE, Brasil. \\ ${ }^{2}$ Universidade Federal da Paraíba, Areia-PB, Brasil. \\ ${ }^{3}$ Departamento de Morfologia e Fisiologia Animal, Universidade Federal Rural de Pernambuco, Recife-PE, Brasil. \\ ${ }^{4}$ Faculdade de Medicina Veterinária e Zootecnia da Universidade de São Paulo, São Paulo- SP, Brasil. \\ *Autor para correspondência/Corresponding author: E-mail: raylson.oliveira@ hotmail.com.br
}

\section{Resumo}

Mannheimia haemolytica é uma bactéria comensal do trato respiratório de bovinos e associada à infecção do trato respiratório desses animais, podendo causar pneumonia, pleurite e septicemia. É considerado o principal agente causador de doenças respiratórias em bovinos. Relata-se um caso de septicemia em um bezerro causado por M. haemolytica. No exame clínico detectou-se taquicardia, taquipneia, respiração abdominal, hipertermia e desidratação. As mucosas oral, nasal e conjuntivais (bilateral) apresentavam-se hiperêmicas, além de um quadro de poliartrite e broncopneumonia. Após cultivo bacteriano do material das articulações e dos pulmões foi possível isolar M. haemolytica. No hemograma foi observado acentuada hiperfibrinogenemia e leucocitose com neutrofilia. No exame necroscópico foram observados poliartrite purulenta. O pulmão apresentou broncopneumonia difusa, além de intensa congestão dos vasos sanguíneos das leptomeninges. Os achados clínicos associados ao exame microbiológico e necroscópico confirmaram o diagnóstico de mannheimiose, sendo este o primeiro relato do envolvimento de M. haemolytica em septicemia em bezerro no Brasil.

Palavras-chave: diagnóstico; infecção; mannheimiose; ruminante.

\begin{abstract}
Mannheimia haemolytica are commensal bacteria from the bovine respiratory tract associated with respiratory infection in these animals, which can cause pneumonia, pleuritis, and septicemia. It is considered the main agent of bovine respiratory diseases. This study records a case of septicemia in a calf caused by M. haemolytica. Tachycardia, tachypnoea, abdominal breathing, hyperthermia, and dehydration were detected during clinical evaluation. Oral, nasal, and conjunctival (bilateral) mucous membranes were hyperaemic; the animal also had polyarthritis and bronchopneumonia. After bacterial cultivation of biological material from articulations and lungs, it was possible to isolate $M$. haemolytica. Accentuated hyperfibrinogenaemia and leucocytosis with neutrophilia were noted in the hemogram. During necropsy, purulent polyarthritis were observed. The lungs presented diffuse bronchopneumonia, and also congestion of the leptomeningeal blood vessels. Clinical findings in association with microbiological evaluation and necropsy confirmed the mannheimiosis diagnosis. This is the first report of M. haemolytica involvement in septicemia of a calf in Brazil.
\end{abstract}

Keywords: diagnosis; infection; mannheimiosis; ruminant. 


\section{Introdução}

Mannheimia haemolytica é uma bactéria comensal da mucosa respiratória do trato superior e nasofaringe de bovinos saudáveis e um dos principais agentes bacterianos do complexo de doenças respiratórias em bovinos, também conhecido como febre dos transportes (Rice et al., 2007; Singh et al., 2011; Mahu et al., 2015).

Em bezerros, $M$. haemolytica pode causar pneumonia após algum processo estressante, associado ou não às infecções virais (Briggs e Frank, 1992; Mahu et al., 2015); a enfermidade também pode estar associada ao estresse causado pelo desmame (Duff e Galyean, 2007; Hanzlicek et al., 2010).

Nos bovinos, a apresentação clínica da enfermidade é caracterizada por desordens respiratórias com corrimento nasal, febre, tosse e perda de peso progressiva, nestes animais, a causa da morte se dá por uma pleuropneumonia fibrinosa aguda (Friend et al., 1977; Rice et al., 2008; Batista et al., 2018). Quadros de septicemia em bezerros são de difícil reversão, bem como quando há o acometimento de vários órgãos, dificultando sua função fisiológica normal (Mahu et al., 2015).

Este trabalho tem como objetivo relatar o primeiro caso clínico de septicemia por Mannheimia haemolytica em um bezerro no estado de Pernambuco, Brasil.

\section{Descrição do Caso}

Um bezerro, macho, girolando, pelagem vermelha e branca com dezesseis dias de idade, proveniente do município de Paulista-PE, criado semi-intensivamente com outros seis bovinos, foi atendido no Ambulatório de Grandes Animais do Hospital Veterinário da Universidade Federal Rural de Pernambuco com histórico de aumento de volume em todas as articulações dos membros torácicos e pélvicos que surgiu após uma vaca pisar sobre a região femoral direita, segundo relatado pelo proprietário. $\mathrm{O}$ proprietário informou que o bezerro desde o nascimento sempre foi apático e permanecia bastante tempo em decúbito lateral. $\mathrm{O}$ motivo pelo qual o mesmo buscou atendimento médico veterinário foi a permanência do bezerro em decúbito lateral há cinco dias, agravado nas últimas 24 horas após o acidente. O proprietário ainda relatou não ter realizado nenhum tratamento e apenas foi feito o aleitamento artificial, não sendo informado o tipo de leite, o volume e a frequência de oferta.
No exame clínico observou-se estado de nutrição ruim, escore de condição corporal 2, taquicardia (184 bpm), taquipneia (136 mpm), respiração abdominal, hipertermia $\left(40,4^{\circ} \mathrm{C}\right)$, turgor cutâneo de 5 segundos e grau de desidratação igual a $10 \%$. As mucosas oral, nasal e conjuntivais (bilateral) apresentavam-se hiperêmicas, havia aumento de volume e crepitação nas articulações cárpicas, társicas e joelhos (Figura 1) de consistência flutuante, hiperextensão dos membros torácicos e pélvicos, amplitude articular aproximada de 5 a 10 graus, decúbito lateral cerca de cinco dias (segundo tutor), opistótono e secreção seropurulenta na narina direita. Os olhos apresentavam vasos episclerais injetados, nistagmo, reflexo do nervo óptico e pupilar negativo, olho direito com edema generalizado de córnea, uveíte, hipópio na câmara anterior e o esquerdo com pupila em miose, presença de flare, discreto descolamento de retina e sinéquia posterior.

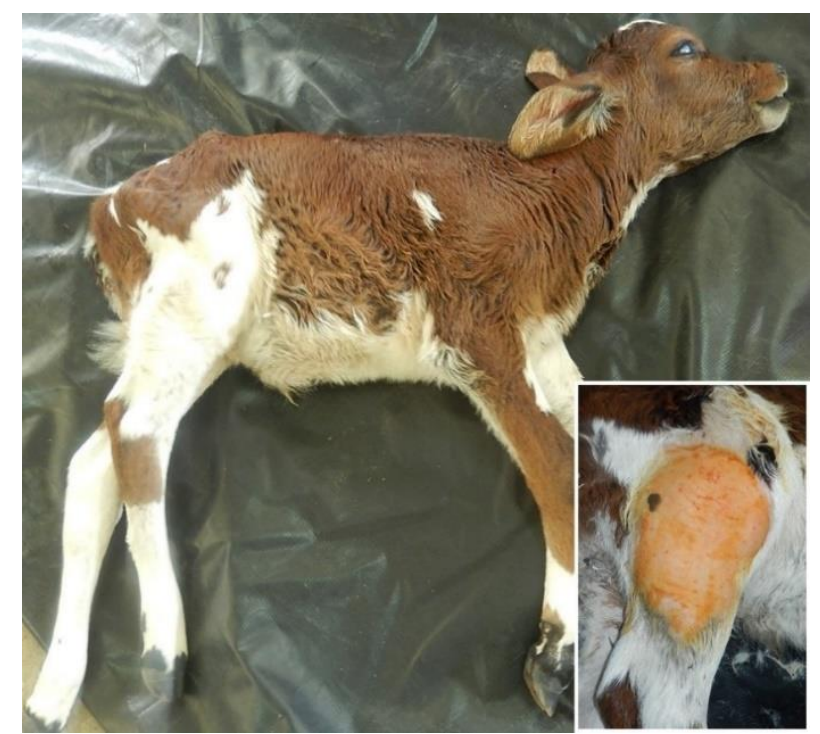

Figura 1. Bezerro em decúbito lateral esquerdo. Aumento de volume da região coxo-lateral. Observar ampliação de aumento de volume da região coxo-lateral direita após tricotomia para coleta de conteúdo.

Todos os esclarecimentos relacionados ao tratamento, agravamento das lesões, prognóstico ruim e comprometimento irreversível do bem-estar do animal foram prestados ao produtor rural. Por não haver alternativa de execução de qualquer medida terapêutica que possibilitasse a recuperação da saúde do mesmo realizou-se eutanásia, com autorização do responsável, conforme preconiza a resolução do CFMV $\mathrm{n}^{\circ} 1.000$, de 11 de maio de 2012. No procedimento 
de eutanásia, utilizou-se cloridrato de xilazina a $2 \% \quad(0,05 \mathrm{mg} / \mathrm{kg})$ endovenosa, seguido de diazepam $(0,5 \mathrm{mg} / \mathrm{kg})$ endovenoso e propofol (4 $\mathrm{mg} / \mathrm{kg}$ ) endovenoso, sendo que o animal veio a óbito após indução anestésica, não sendo necessário o uso de nenhum fármaco para tal finalidade.

Antes da eutanásia foram coletados sangue para hemograma e conteúdo purulento das articulações e pulmões por punção aspirativa para exame microbiológico.

O hemograma revelou acentuada hiperfibrinogenemia, e leucocitose com neutrofilia, com desvio à esquerda regenerativo. Foram observados valores de eritrócitos $6,53 \times 10 \% \mu \mathrm{L}$, hematócrito 32,0\%, VCM (volume corpuscular médio) 49,0\%, PPT (proteínas plasmáticas totais) 7,4g/dl, FP (fibrinogênio plasmático) $1900 \mathrm{mg} / \mathrm{dL}$,

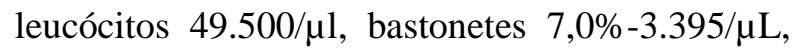
segmentados $75 \%-36.375 / \mu \mathrm{L}$, linfócitos $15 \%$ -

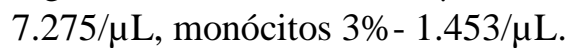

$\mathrm{O}$ resultado da cultura do conteúdo das articulações e pulmões, realizado em ágar base acrescido de 7\% de sangue ovino em estufa bacteriológica a $37^{\circ} \mathrm{C}$ por $48 \mathrm{~h}$ sob aerobiose, indicou crescimento de Mannheimia, o crescimento foi exuberante e puro de pequenas colônias bacterianas de coloração acinzentadas. $\mathrm{Na}$ coloração pelo método de Gram foi possível visualizar pequenos cocobacilos Gram negativos; e a posterior identificação da $M$. haemolytica foi realizada pelo VITEK ${ }^{\circledR} 2$ Compact (bioMérieux, France), obtendo uma concordância de $99 \%$ para esta espécie bacteriana.

À abertura das articulações notou-se quadro de poliartrite séptica com inflamação fibrinopurulenta das articulações cárpicas, tíbio-társicas e femorotibiopatelar (Figura 2). O pulmão apresentava broncopneumonia disseminada com maior comprometimento do lobo caudal esquerdo. A abertura da calota craniana demonstrou intensa congestão dos vasos sanguíneos das leptomeninges. Com relação aos outros órgãos analisados na necropsia, não foram observadas alterações dignas de nota.
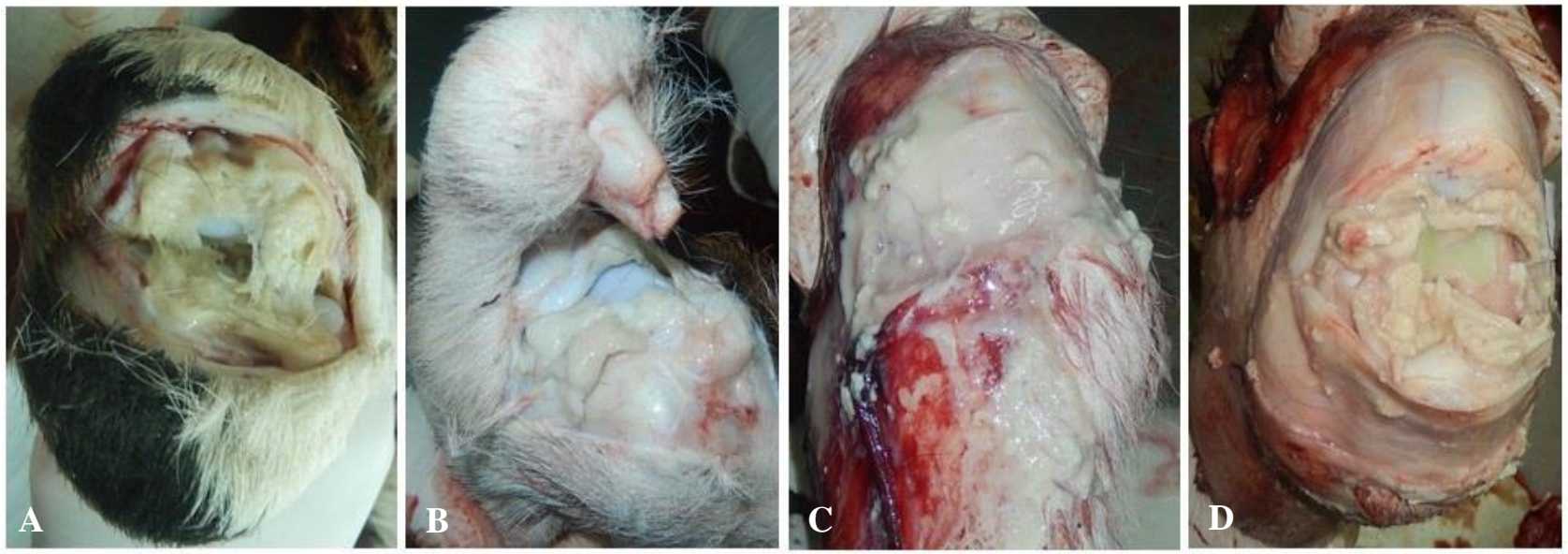

Figura 2. Poliartrite séptica em bezerro. (A) Artrite fibrino purulenta em articulação cárpica e (B) fibrinosa em articulação tíbio-társica; notar deposição de placas esbranquiçadas sobre as cartilagens. (C e D) Processo inflamatório supurativo com osteomielite em região de côndilos e fossa intercondilar em articulação femorotibiopatelar.

\section{Discussão}

O quadro clínico do animal, associado aos exames complementares como hemograma, achados de necropsia e a cultura microbiológica, confirmaram um quadro de septicemia por $M$. haemolytica. A cultura microbiológica é indispensável para a identificação do agente causador desta enfermidade, principalmente quando este é isolado de regiões diferentes no corpo do animal, como no presente caso em que $M$. haemolytica foi isolada das articulações e pulmões, sendo este o agente isolado com maior frequência nos casos de doenças respiratórias em bovinos (Ferguson et al., 2011; Harada et al., 2019).

A infecção por $M$. haemolytica geralmente apresenta evolução aguda, podendo o animal apresentar-se em decúbito em até 24 horas, como observado neste relato. Esse quadro também foi descrito por Fagliari (2003), nos quais bezerros apresentaram coma com evolução de 24 horas, após inoculação intrabronquial de $M$. haemolytica.

Quadro clínico de septicemia em bezerros lactentes são causados principalmente por falta de cuidados em relação à cura do umbigo ou a não 
ingestão do colostro nas primeiras horas após o parto (Rodrigues et al., 2010), contudo isso não foi observado nesse caso. A infecção deve ter tido origem pulmonar, pois $M$. haemolytica é comensal do trato respiratório superior de bovinos sadios (Singh et al., 2011).

Na literatura é comum a descrição de surtos de septicemia em cordeiros por algumas bactérias da família Pasteurellaceae na qual a $M$. haemolytica está inserida, porém em bovinos os relatos e estudos se concentram nos casos de pneumonias, principalmente em animais no início do confinamento devido ao estresse ocasionado pelo desmame (Singh et al., 2011; Retore e Correa, 2015).

Sinais clínicos como febre, taquipneia, taquicardia, aumento no tempo de turgor cutâneo, decúbito e até mesmo coma foram achados semelhantes aos descritos por Mahu et al. (2015) em um quadro clínico de um bezerro com septicemia ocasionado por $M$. haemolytica na Bélgica e em casos de pneumonia experimentalmente induzida em bezerros por esta bactéria (Fagliari, 2003).

As alterações apresentadas no hemograma são sugestivas de um quadro inflamatório infeccioso com aumento no fibrinogênio e células da série branca do sangue com destaque para bastonetes e segmentados. A alteração nos níveis de fibrinogênio pode estar relacionada à pneumonia e poliartrite, pois em grandes animais este é o primeiro indicativo de alterações inflamatórias e o aumento dos bastonetes e segmentados está intimamente relacionado ao processo infeccioso de origem bacteriana (Fagliari et al., 1998; Fagliari, 2003; Borges et al., 2006).

As alterações macroscópicas nas articulações, cérebro e principalmente nos pulmões, associadas ao isolamento bacteriano comprovam um quadro clínico de septicemia e os achados nos pulmões sugerem uma broncopneumonia aguda em animais com mannheimiose.

\section{Conclusão}

Os achados clínicos associados ao exame microbiológico e necroscópico confirmam o diagnóstico de mannheimiose, sendo este o primeiro relato do envolvimento de Mannheimia haemolytica causando septicemia em bezerro no Brasil.

\section{Conflito de Interesse}

Não temos conflito de interesse a declarar.

\section{Referências}

Batista, C.F.; Souza, F.N.; Santos, K.R.; Sanchez, E.M.R.; Reis, L.C.; Bertagnon, H.G.; Della Libera, A.M. R-Phycoerythrin-labeled Mannheimia haemolytica for the simultaneous measurement of phagocytosis and intracellular reactive oxygen species production in bovine blood and bronchoalveolar lavage cells. Veterinary Immunology and Immunopathology, 196: 53-59, 2018.

Borges, N.C.; Vieira, D.; Silva, L.A.F.; Fioravanti, M.C.S. Valores leucocitários e nível de fibrinogênio plasmático de bovinos com pododermatite. Ciência Animal Brasileira, 7(1): 97-102, 2006.

Briggs, R.E.; Frank, G.H. Increased elastase activity in nasal mucus associated with nasal colonization by Pasteurella haemolytica in infectious bovine rhinotracheitis virus infected calves. American Journal of Veterinary Research, 53(5): 631-635, 1992.

Conselho Federal De Medicina Veterinária CFMV. Dispõe sobre procedimentos e métodos de eutanásia em animais e dá outras providências. Resolução n ${ }^{\circ} 1000$ de 11 de Maio de 2012. Disponível em: $<$ http://portal.cfmv.gov.br/lei/downloadarquivo/id/325>. Acesso em: 23 jul. 2019.

Duff, G.C.; Galyean, M.L. Board-invited review: recent advances in management of highly stressed, newly received feedlot cattle. Journal of Animal Science, 85(3): 823-840, 2007.

Fagliari, J.J.; Santana, A.E.; Lucas, F.A.; Campos, E.; Curi, P.R. Constituintes sanguíneos de bovinos recém-nascidos das raças Nelore (Bos indicus) e Holandesa (Bos taurus) e de bubalinos (Bubalus bubalis) da raça Murrah. Arquivo Brasileiro de Medicina Veterinária e Zootecnia, 50(3): 253-262, 1998.

Fagliari, J.J. Estudo clínico e laboratorial da pneumonia de bezerros induzida pela inoculação intrabronquial de Mannheimia haemolytica. Arquivo Brasileiro de Medicina Veterinária e Zootecnia, 55(1): 8-14, 2003.

Ferguson, S.H.; Rech, R.R.; Howerth, E.W. Pathology in practice. Mannheimia haemolytica. Journal of the American Veterinary Medical Association, 239(11): 1437-1439, 2011. 
Friend, S.C.; Wilkie, B.N.; Thomson R.G.; Barnum, D.A. Bovine pneumonic pasteurellosis: experimental induction in vaccinated and nonvaccinated calves. Canadian Journal of Veterinary Research, 41(1): 77-83, 1977.

Hanzlicek, G.A.; White, B.J.; Mosier, D.; Renter, D.G.; Anderson, D.E. Serial evaluation of physiologic, pathological, and behavioral changes related to disease progression of experimentally induced Mannheimia haemolytica pneumonia in postweaned calves. American Journal of Veterinary Research, 71(3): 359-369, 2010.

Harada, N.; Takizawa, K.; Matsuura, T.; Yokosawa, N.; Tosaki, K.; Katsuda, K.; Shibahara, T. Bovine peritonitis associated with Mannheimia haemolytica serotype 2 in a threeday-old Japanese Black calf. Journal of Veterinary Medical Science, 81(1): 143-146, 2019.

Mahu, M.; Valgaeren, B.; Pardon, B.; Deprez, P.; Haesebrouck, F.; Boyen, F. Non-haemolytic
Mannheimia haemolytica as a cause of pleuropneumonia and septicemia in a calf. Veterinary Microbiology, 180(1-2): 157-160, 2015.

Retore, M.; Correa, E.B. Principais doenças diagnosticadas nos rebanhos ovinos de Mato Grosso do Sul. Dourados: Embrapa Agropecuária Oeste. 2015. 55p.

Rice, J.A.; Carrasco-Medina, L.; Hodgins, D.C.; Shewen, P.E. Mannheimia haemolytica and bovine respiratory disease. Animal Health Research Reviews, 8(2): 117-128, 2007.

Rodrigues, C.A.; Santos, P.S.P.D.; Perri, S.H.V.; Teodoro, P.H.M.; Anhesini, C.R.; Araújo, M.A.D.; Viana Filho, M.N. Correlação entre os métodos de concepção, ocorrência e formas de tratamento das onfalopatias em bovinos: estudo retrospectivo. Pesquisa Veterinária Brasileira, 30(8): 618-622, 2010.

Singh, K.; Ritchey, J.W.; Confer, A.W. Mannheimia haemolytica: bacterial-host interactions in bovine pneumonia. Veterinary Pathology, 48(2): 338-348, 2011. 